\title{
Clinicopathological and Radiological Features with Long Term Follow Up of Metaplastic Carcinoma Breast in India
}

\author{
Gopal Puri', Kush Raj Lohani ${ }^{1}$, Sarada Khadka ${ }^{1}$, Kamal Kataria ${ }^{1 *}$, Piyush \\ Ranjan', Smriti Hari², Sandeep Mathur ${ }^{3}$, Anita Dhar', Anurag Srivastava1
}

\begin{abstract}
Objective: Metaplastic breast carcinoma (MBC) is a heterogeneous group of invasive carcinomas with squamous and/or mesenchymal differentiation. Because of their rare occurrence, the information regarding the clinical behaviour of metaplastic carcinomas is limited. The purpose of our study was to delineate the clinicopathological and radiological features, treatment outcomes, prognostic factors, and survival of patients with MBC. Methods: Ambispective observational study with prospective recruitment was done from $1^{\text {st }}$ January 2019 to $31^{\text {st }}$ August 2020. Retrospective data included between $1^{\text {st }}$ January 2009 and $31^{\text {st }}$ December 2018. In the retrospective group surgical database of our department was searched and those with MBC diagnosis on post-operative histopathology recruited. In prospective group patients with $\mathrm{MBC}$ on core biopsy were followed and those operated were included. The patients followed up at our breast cancer clinic (BCC) and their demographic, clinical, pathological radiological and treatment details noted. Results: Forty patients formed the study population. The mean age of the patents was 42 years. Ipsilateral axillary lymph node metastasis was present in $22.5 \%$. The pathological median tumor size was 5.4 (range 2.1 to $22 \mathrm{~cm}$ ). The most common differentiation was cartilaginous (35\%) followed by squamous $(32.5 \%)$. The most common mammographic grading was BIRADS 4 (Breast Imaging Reporting and Data system). Magnetic resonance imaging was T2 hyperintense with peripheral rim enhancement and restriction on DWI. The median overall (OS) and disease-free survival (DFS) was 42 and 40 months, respectively. Fifteen patients (37.5\%) had disease related mortality. A subgroup analysis revealed that, type of differentiation, histopathology and tumor size $>5 \mathrm{~cm}$ affected both OS and DFS significantly. Conclusion: Metaplastic breast cancer in our setup presents in young patients with aggressive large tumors at a higher stage and diverse histopathology and with comparable overall and disease-free survival. The histological subtype, tumor differentiation and tumor size are prognostic factors.
\end{abstract}

Keywords: Metaplastic breast carcinoma- triple negative breast cancer- overall and disease-free survival

Asian Pac J Cancer Prev, 22 (11), 3483-3492

\section{Introduction}

Traditionally the incidence of Metaplastic Breast Carcinoma (MBC) is $0.2 \%-5 \%$ of all invasive breast cancers (Lakhani et al., 2012). However, the recent studies have reported the incidence to be between $0.5 \%-2.2 \%$ (Hashmi et al., 2018; Moorman et al., 2020). Metaplastic breast cancer is a diverse group of invasive carcinomas with squamous with or without mesenchymal differentiation. They have an aggressive course. Based on histological characters, $\mathrm{MBC}$ has been classified into seven main types: matrix-producing/mesenchymal carcinoma, cartilaginous, spindle cell carcinoma, squamous cell carcinoma, osseous, sarcomatoid and adenosquamous (Lakhani et al., 2012). The immunohistochemical studies reveal primarily ER, PR negative and HER2/neu negative, but this is not absolute.
There are other non-conventional immunohistochemical markers like cytokeratin, vimentin, S100, SMA4, BCL2, CD34 and P63

The clinical presentation of these cancers, in hindsight, reveal aggressively fast-growing, large tumors with paradoxically less rates of axillary metastasis at diagnosis (Alam et al., 2003; Lai et al.,2013). They are notorious to metastasise to the lungs among other organs. They portend a grave prognosis. Due to the lack of data, there are no clear guidelines on the specific management of these tumors and they are generally managed as the usual Invasive Ductal Carcinomas (IDC). Surgical management is the mainstay. Either breast conservation surgery (BCS) or mastectomy is done based on the tumor size and the breast tissue. The traditional chemotherapy drugs used in IDC have not shown much benefit in the MBC. Role of hormonal

${ }^{1}$ Department of Surgical Disciplines, All India Institute of Medical Sciences, New Delhi, India. ${ }^{2}$ Department of Radiodiagnosis, All India Institute of Medical Sciences, New Delhi, India. ${ }^{3}$ Department of Pathology, All India Institute of Medical Sciences, New Delhi, India. *For Correspondence: drkamalkataria@gmail.com 
therapy is minimal with no role of HE2/neu inhibitors as most of these are triple negative breast cancers (TNBC) (Rayson et al., 1999; Aydiner et al.,2015). Radiation was earlier used only in the adjuvant setting (Pitts et al., 1991). Now recently conducted studies have shown that long term outcomes improved with neo-adjuvant chemotherapy and combined chemotherapy and radiotherapy (Li et al., 2019; Wang et al., 2019). The immunological studies have demonstrated a potential role of immunotherapy as it has high levels of PD-L1 and tumor infilterating T lymphocytes (Gadaleta-Caldarola et al., 2021).

Because of the rare occurrence of $\mathrm{MBC}$, the information regarding the clinical behaviour and tumor biology of metaplastic carcinomas is scarce and is primarily based on small retrospective studies. Hence, the present study was designed to evaluate overall survival, disease free survival, clinical outcomes and prognostic factors of patients with histologically diagnosed MBC.

\section{Materials and Methods}

\section{Study Design}

An ambispective observational study was conducted in the department of surgical disciplines at the All India Institute of Medical Sciences, New Delhi, India with prospective recruitment done from 1st January 2019 to $31^{\text {st }}$ August 2020. Retrospective data included patients operated in between the period of 1st January 2009 to $31^{\text {st }}$ December 2018.

\section{Methodology}

The surgical database of our department was searched for the term metaplastic carcinoma and the patients with confirmed post-operative histopathological report were recruited in the retrospective group. These patients were under regular follow up at our breast cancer clinic (BCC). The demographic, clinical, pathological radiological and treatment details of the patients were noted in their BCC file. They were called for follow up regularly to the BCC at an interval of 3 months for the first 2 years, then 6 monthly for another 3 years and annually thereafter. The BCC file was updated at each visit. During the COVID-19 pandemic, the follow up was done via teleconsultations involving voice and video calls.

\section{Inclusion and Exclusion Criteria}

For the retrospective group patients with a confirmed of metaplastic carcinoma on the histopathology of the surgically excised specimen were included. Only those which were operated between the recruitment period were included. The patients which not operated (due to various reasons), but $\mathrm{MBC}$ was suspected on the core biopsy were excluded from recruitment. Similarly in the prospective group, all the patients with suspected diagnosis on a core biopsy followed up and only the ones operated were included after the diagnosis was confirmed by the operative specimen histopathology.

\section{Statistical Analysis}

Mean of variables was calculated when the data was evenly distributed and median when the variable was skewed. Survival analysis was done using Kaplan-Meier curves using sigma plot 12.3 software. The overall (OS) and Disease-free survival (DFS) was calculated and compared for the subgroup analysis to delineate the prognostic factors. A study from the western population was selected with a similar design and sample size for comparison (El Zein et al., 2017)

\section{Results}

A total of 51 patients were considered for recruitment. Forty-four patients were in the retrospective group out of which 3 were excluded due to metastasis at diagnosis and hence, were not operated. Six patients (13.04\%) were lost to follow up so excluded from the final analysis. Out of the 7 patients in the prospective group, 2 were excluded as they were receiving NACT at the conclusion of recruitment period and were not operated. Thus, a total of 40 cases were included for further analysis (35 retrospective and 5 prospective). Due to small numbers, only a combined analysis was performed.

\section{Clinical Features}

The mean age of 40 patients was 42 years with standard deviation of 12 years. Twenty-two (55\%) patients were pre-menopausal at the time of diagnosis. Twenty-three patients $(57.5 \%)$ had a T3 tumor and $9(22.5 \%)$ patients had metastasis to the ipsilateral axillary lymph nodes. Fifteen $(37.5 \%)$ patients were Stage III at presentation and $17(42.5 \%)$ had received neo-adjuvant chemotherapy. Twenty-seven (67.5\%) patients underwent mastectomy and breast conservation surgery could only be done in remaining 13 (32.5\%) ladies. Table 1 delineates the details of clinical and pathological features.

\section{Pathological Features}

On gross examination, these tumors were scirrhous with regular or irregular margins (Figure 1A). The pathological tumor size ranged from $2.1 \mathrm{~cm}$ to a whopping $22 \mathrm{~cm}$ with a median tumor size of $5.4 \mathrm{~cm}$. The most common differentiation was cartilaginous in $14(35 \%)$ followed by squamous (32.5\%) (Figure 1B, 1C). Twelve $(30 \%)$ tumors had more than one type of differentiation with the rest having a pure metaplastic component. There was lympho-vascular invasion in 18 $(45 \%)$ cases and is depicted in Figure 1D. Necrosis was seen in $32(80 \%)$ tumors. Only 2 cases were ER and PR positive with Her2neu negative. There were a variety of immunohistochemical markers seen, with cytokeratin $(50 \%)$ and vimentin $(35 \%)$ (Figure $1 \mathrm{E}, 1 \mathrm{~F})$ being the most common (Table 1).

\section{Radiological Features}

The radiological features were noted in only 22 patients whose investigations were done at our centre. Metaplastic breast cancer on ultrasonography showed diverse range of findings from being a complex cystic lesion to a hypoechoic mass with micro-lobation (Figure 2C, 2F). The mammographic findings are summarised in Table 2. American College of Radiology grade D breast density was seen in $9(40.1 \%$ ) cases and BIRADS 4 (Figure 2) 


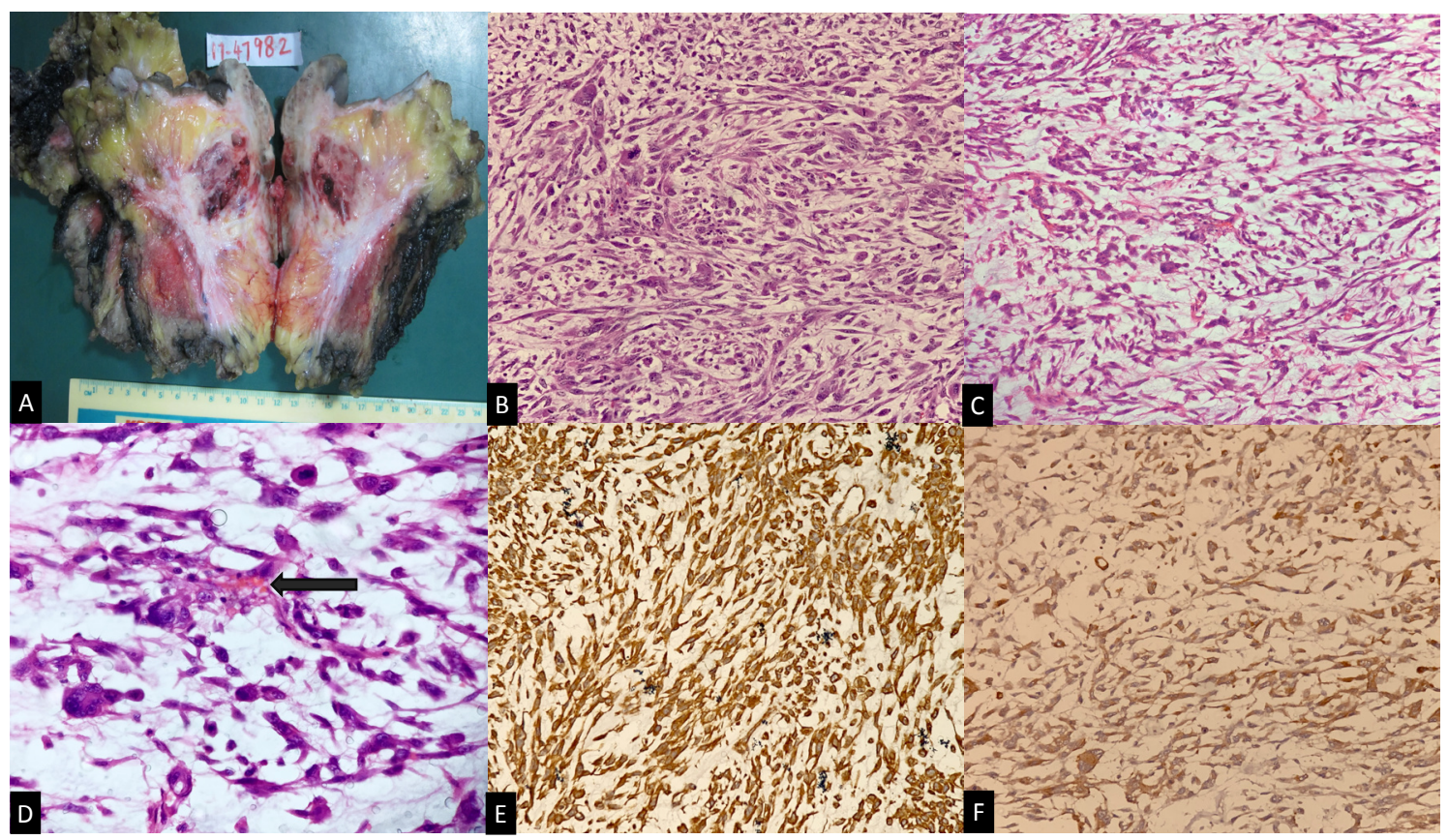

Figure 1. Gross and Histopathological Images of Metaplastic Bbreast Carcinoma(MBC). A, Gross specimen with scirrhous centre depicting the mesenchymal differentiation; B, HPE 20X depicting Cartilagenous variant of MBC; C, HPE 20X depicting Squamous variant of MBC; D, HPE 40X with marked arrow at the vascular invasion by the tumour emboli; E, Immunohistochemical marker Cytokertain-stained MBC; F, Immunohistochemical marker Vimentin-stained MBC

was the most common mammographic grading reported. Magnetic resonance imaging was done for the 2 cases with only focal asymmetry without any mass lesion. The core biopsy was taken by ultrasonographic guidance in these cases. The MBC was heterogenous T2 hyperintense with peripheral rim enhancement and restriction on diffusion weighted imaging (Figure 3).

\section{Clinical Outcomes and Survival}

At the end of the study period (last follow up visit on 30th January 2021) 18(45\%) were alive and disease free, $5(12.5 \%)$ were alive with the disease and there were 17 (42.5\%) mortalities. Out of these, 2 (11.7\%) mortalities were from non-disease related causes. Of the $15(88.23 \%)$ disease related mortalities, lung metastasis was present in $8(53.33 \%)$ cases, metastasis to other organs was seen in $5(33.33 \%)$ patients and $2(13.34 \%)$ had loco-regional

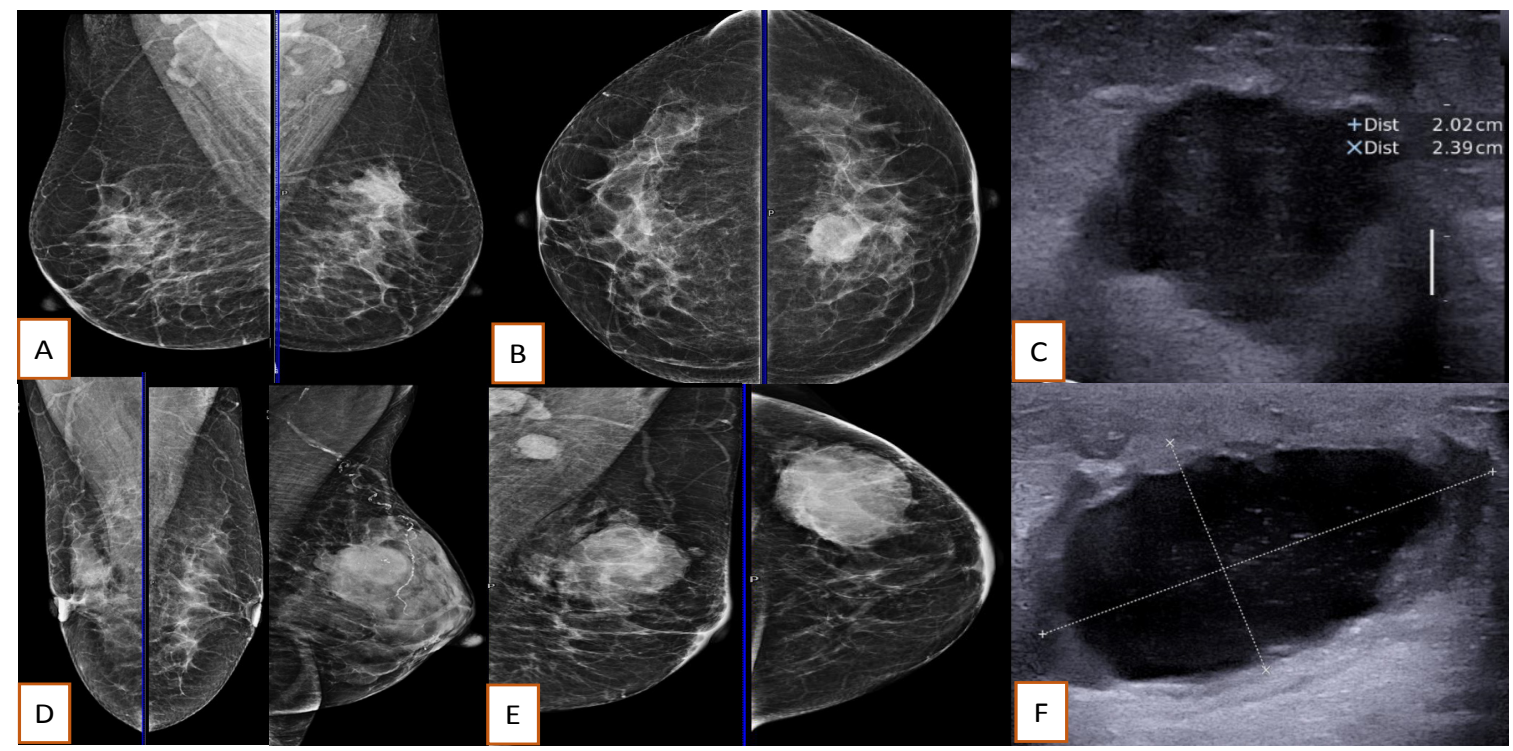

Figure 2. Mammo-sonographic images of Metaplastic Breast Carcinoma(MBC). A \& B, Irregularly shaped highdensity mass with indistinct margins (BIRADS 4c) in a mammogram of a 47 year old lady; C, Ultrasonography of the same lady depicting the mass to be hypoechoic with micro-lobated margins; D, Mammogram of two ladies showing iso-dense oval mass with pleomorphic calcification (BIRADS 4c); E, Mammogram of 41 year old lady with oval highdensity circumscribed mass with partly indistinct margins with skin thickening and axillary nodes (BIRADS 4b); F, Ultrasonography of the same lady with complex cystic lesion 
Table 1. Clinico-Pathological Findings of the Patients of Metaplastic Breast Cancer( $\mathrm{n}=40)$

\begin{tabular}{|c|c|c|}
\hline \multicolumn{2}{|c|}{ Clinicopathological Parameters } & \multirow{2}{*}{$\frac{\text { Value }}{42.10}$} \\
\hline Age (Years) & Mean & \\
\hline & SD & 12.19 \\
\hline \multirow{2}{*}{$\begin{array}{l}\text { Menopausal } \\
\text { Status }\end{array}$} & Pre-Menopausal & $22(55 \%)$ \\
\hline & Post-Menopausal & $18(45 \%)$ \\
\hline \multirow[t]{2}{*}{ Tumour Staging } & $\mathrm{T} 2$ & $17(42.5 \%)$ \\
\hline & $\mathrm{T} 3$ & $23(57.5 \%)$ \\
\hline \multirow[t]{3}{*}{ Nodal Staging } & N1 & $6(15 \%)$ \\
\hline & N2 & $2(5 \%)$ \\
\hline & N3 & $1(2.5 \%)$ \\
\hline \multirow[t]{2}{*}{ TNM Staging } & Stage II & $25(62.5 \%)$ \\
\hline & Stage III & $15(37.5 \%)$ \\
\hline NACT Given & & $17(42.5 \%)$ \\
\hline \multirow[t]{2}{*}{ Hormonal Status } & Triple Negative & $38(95 \%)$ \\
\hline & ER PR + Her2neu - & $2(5 \%)$ \\
\hline \multirow{3}{*}{$\begin{array}{l}\text { Surgery } \\
\text { Performed }\end{array}$} & WLE plus SLNB +/- ALND & $13(32.5 \%)$ \\
\hline & Simple mastectomy Plus SLNB & $13(32.5 \%)$ \\
\hline & MRM & $14(35 \%)$ \\
\hline \multirow{3}{*}{$\begin{array}{l}\text { Pathological } \\
\text { Tumour size }(\mathrm{cm})\end{array}$} & Median & 5.40 \\
\hline & Mean with SD & $6.5+/-4.6$ \\
\hline & Range & 2.1 to 22 \\
\hline \multirow{2}{*}{$\begin{array}{l}\text { Histopathological } \\
\text { Hallmarks }\end{array}$} & Necrosis & $32(80 \%)$ \\
\hline & Lympho-vascular Invasion & $18(45 \%)$ \\
\hline \multirow{6}{*}{$\begin{array}{l}\text { Predominant type } \\
\text { of differentiation }\end{array}$} & Cartilaginous & $14(35 \%)$ \\
\hline & Squamous & $13(32.5 \%)$ \\
\hline & Adeno-squamous & $4(10 \%)$ \\
\hline & Osseous & $3(7.5 \%)$ \\
\hline & Sarcomatoid & $2(5 \%)$ \\
\hline & Spindle cell & $4(10 \%)$ \\
\hline \multirow[t]{2}{*}{ Histology } & Pure metaplastic & $28(70 \%)$ \\
\hline & Mixed metaplastic & $12(30 \%)$ \\
\hline \multirow{7}{*}{$\begin{array}{l}\text { IHC markers } \\
\text { (Multiple positive } \\
\text { can be present) }\end{array}$} & Cytokeratin & $20(50 \%)$ \\
\hline & Vimentin & $14(35 \%)$ \\
\hline & S-100 & $12(30 \%)$ \\
\hline & SMA & $6(15 \%)$ \\
\hline & BCL-2 & $4(10 \%)$ \\
\hline & CD 34 & $2(5 \%)$ \\
\hline & P63 & $4(10 \%)$ \\
\hline \multirow{4}{*}{$\begin{array}{l}\text { Clinical } \\
\text { Outcomes }\end{array}$} & Alive and disease free & $18(45 \%)$ \\
\hline & Alive with local recurrence & $2(5 \%)$ \\
\hline & Alive with Distant metastasis & $3(7.5 \%)$ \\
\hline & Mortality & $17(42.5 \%)$ \\
\hline
\end{tabular}

ALND, Axillary Lymph Node Dissection; BCL-2, B cell CLL/ lymphoma-2; CD, Cluster of differentiation; MRM, Modified Radical Mastectomy; SD, Standard Deviation; SLNB, Sentinel Lymph Node Biospy; SMA, Smooth muscle antigen; WLE, Wide Local Excision.

recurrence with intrathoracic extension without distant metastasis. Out of the 40 patients the follow up period of 10 patients was less than 2 years, so they were excluded from the survival analysis. Apart from this, the 2 patients which died of non-disease related conditions (acute myocardial infarction) are also excluded. Hence, the
Table 2. Mammo-Sonographic Findings of Metaplastic Breast Carcinoma

\begin{tabular}{llc}
\hline \multicolumn{2}{l}{ Radiological Parameters } & $\begin{array}{c}\text { No. of Patients } \\
(\mathrm{n}=22)\end{array}$ \\
\hline $\begin{array}{l}\text { ACR Category of } \\
\text { Breast Density }\end{array}$ & A & 0 \\
& B & $6(27.27 \%)$ \\
& D & $7(31.81 \%)$ \\
BIRADS & Category 3 & $9(40.10 \%)$ \\
Classification (On & Category 4 & $2(9.09 \%)$ \\
Mammo-sonography) & Category 5 & $10(45.45 \%)$ \\
Abnormal & Category 6 & $7(31.81 \%)$ \\
Findings & Mass lesion & $3(13.63 \%)$ \\
Margins of the lesion & Spiculated & $20(90.90 \%)$ \\
& Partially circumscribed & $2(9.09 \%)$ \\
Shape of the mass & Oval & 0 \\
lesion & Irregular & $12(54.54 \%)$ \\
Miscellaneous & Suspicious Nodes & $8(36.36 \%)$ \\
features & Pleomorphic Calcification & $3(13.63 \%)$ \\
\hline ACR Ammetry & $4(18.18 \%)$ \\
\hline
\end{tabular}

ACR, American College of Radiology.

survival analysis is done for 28 patients. The median overall (OS) and disease-free survival (DFS) was 42 and 40 months, respectively. A subgroup analysis of OS and DFS is depicted in table 3. It revealed that, type of differentiation, histopathology and tumor size $>5$ $\mathrm{cm}$ affected both OS and DFS significantly. Axillary lymph node involvement reduced OS from 63 months to 35 months (Table 3 ). Other prognostic factors such as menopausal status, tumor necrosis and lympho-vascular invasion did not affect survival. The Kaplan-Meier curves of these analysis are depicted in Figure 4.

\section{Discussion}

This study presents clinical features, outcomes, and prognostic factors of forty patients of $\mathrm{MBC}$, managed at our tertiary care institute. Generally, MBC presents with bigger size, higher grade and stage, triple negative hormone receptors with less metastasis to the lymph nodes and more possibility of distant metastasis when compared with Invasive Ductal Carcinoma (IDC) (Lai et al.,2013; Vias et al.,2019). Patients with MBC usually present at a median age of around 60 years (Rayson et al., 1999) while earlier diagnosis at the mean age of 50 years is also reported (Pitts et al., 1991). However, our patient presented at a markedly younger age of 42 years. The axillary lymph nodes involvement was $22.5 \%$ in our cohort. There are huge discrepancies in the prevalence of the lymph node metastasis which ranges from 0-63\% according to various studies (Pitts et al., 1991; Al Sayed et al., 2006; Leddy et al., 2012; Lee et al., 2012; Schwartz et al., 2013; Song et al., 2013; Zhang et al., 2015) but is considered to be around $26 \%$. This is considerably lower than the percentage of involvement in the IDC (30-45\%) (Song et al., 2013).

Due to the rarity of this tumor, there are no standardised 
Table 3. Survival Analysis and the Subgroup Analysis of the Prognostic Factors in MBC $(n=28)$

\begin{tabular}{|c|c|c|c|c|}
\hline Group & $\begin{array}{l}\text { Overall survival (months) } \\
\text { [95\% Confidence Interval) }\end{array}$ & P value & $\begin{array}{l}\text { Disease free survival (months) } \\
\text { [95\% Confidence Interval) }\end{array}$ & $P$ value \\
\hline Survival of the Cohort & $42(7.3-76.6)$ & N.A & $40(7.5-72.4)$ & N.A \\
\hline \multicolumn{5}{|l|}{ Menstrual status } \\
\hline Post-menopausal (n=7) & Not Reached & 0.35 & Not Reached & 0.26 \\
\hline Pre-menopausal (n=21) & $42(7.8-76.1)$ & & $40(3.2-76.7)$ & \\
\hline \multicolumn{5}{|l|}{ Axillary lymph node } \\
\hline Positive $(\mathrm{n}=7)$ & $35(29.2-40.7)$ & 0.63 & $33(24.7-41.2)$ & 0.62 \\
\hline Negative $(n=21)$ & $63(35.9-90)$ & & $60(28-91.9)$ & \\
\hline Neo-adjuvant chemotherapy & Not Reached & & & \\
\hline Yes $(n=12)$ & $42(29.7-54.2)$ & 0.61 & $65(4.8-125.1)$ & 0.9 \\
\hline No $(n=16)$ & & & $40(10.9-69)$ & \\
\hline \multicolumn{5}{|l|}{ Tumor size } \\
\hline$>5 \mathrm{~cm}(\mathrm{n}=18)$ & $30(8.3-51.6)$ & 0.06 & $24(-9.2-57.2)$ & 0.02 \\
\hline$<5 \mathrm{~cm}(\mathrm{n}=10)$ & Not Reached & & Not Reached & \\
\hline \multicolumn{5}{|l|}{ Tumor Necrosis } \\
\hline Yes $(n=24)$ & $36(21.3-50.6)$ & 0.13 & $40(11-68.9)$ & 0.04 \\
\hline No $(n=4)$ & Not Reached & & Not Reached & \\
\hline \multicolumn{5}{|l|}{ Tumor differentiation } \\
\hline Cartilagenous $(\mathrm{n}=8)$ & Not Reached & 0.002 & Not Reached & $<0.001$ \\
\hline Squamous $(\mathrm{n}=9)$ & $63(-4.4-130.4)$ & & $60(25.3-94.6)$ & \\
\hline Adenosquamous $n=4$ ) & $16(6.2-25.8)$ & & $15(5.2-24.8)$ & \\
\hline Osseous ( $(n=2)$ & $23(-$ inf to + inf $)$ & & $20(-$ inf to + inf $)$ & \\
\hline Sarcomatoid $(n=2)$ & $13(-5-31)$ & & $5(-7.4-17.4)$ & \\
\hline Spindle cell $(n=3)$ & $14(10.7-17.2)$ & & $12(5.5-18.4)$ & \\
\hline \multicolumn{5}{|l|}{ MBC Histopathology } \\
\hline Mixed (n=8) & $16(4.9-27)$ & 0.002 & $15(6.6-23.3)$ & $<0.001$ \\
\hline Pure $(n=20)$ & Not Reached & & $65(26-103.9)$ & \\
\hline \multicolumn{5}{|l|}{ Lymphovascular invasion } \\
\hline Yes $(n=12)$ & $36(27.3-44.6)$ & 0.34 & $33(21.9-44)$ & 0.28 \\
\hline No $(n=16)$ & Not Reached & & $65(22.7-107.2)$ & \\
\hline
\end{tabular}

protocols for the management of this subtype (Gradishar et al., 2017). But given the poor response to chemotherapy, surgical excision is considered the primary modality of treatment (Corso et al., 2021). Majority of the cases underwent mastectomy owing to the large tumor size at presentation and BCS was done only in $32.5 \%$ of our patients. Recently published study done on the Surveillance, Epidemiology, and End Results (SEER) database concluded that BCS conferred better OS and breast cancer specific survival as compared to mastectomy and this was seen for all $\mathrm{T}$ stages and $\mathrm{N}$ stages, except for N2-3 disease (Zhang et al., 2021). Neoadjuvant chemotherapy was given to $42.5 \%$ cases, this is lower than the data reported in literature for MBC (53.4\%) (Pezzi et al., 2007). However, the recent studies have reported up to $90 \%$ patients receiving chemotherapy in the form of neoadjuvant therapy and adjuvant therapy (Hennessy et al., 2006; Fayaz et al.,2017). Administration of combined chemotherapy and radiotherapy in cases with node positive cases has shown to prevent micro-metastasis and improve the survival outcomes (Ma et al., 2021).

The pathological features demonstrate the actual uniqueness of this type over the IDC. Metaplastic breast cancer is known for larger tumor sizes. The mean tumor size reported for IDC is $2.7 \mathrm{~cm}$ as compared to $5 \mathrm{~cm}$ for the metaplastic variant (Yu et al., 2015; El Zein et al., 2017; Donato et al., 2018). The recent studies report a median size of $2.2 \mathrm{~cm}$ even in MBC cases (Moorman et al., 2020). The median tumor size in our study was $5.4 \mathrm{~cm}$ ranging from $2.1 \mathrm{~cm}$ to $22 \mathrm{~cm}$. However, there are other studies also which have reported unusually large tumors (AbbasZadeh, 1992). Metaplastic breast cancer has distinct types of differentiation and the types can co-exist. There are studies that has associated these subtypes with outcome. The matrix- producing tumors had the best outcome while the spindle, mixed spindle and squamous carcinomas had the worst outcome, and this was an independent prognostic variable (Beatty et al., 2006; Nayak et al., 2013; Tadros et al., 2021). In comparison to this, our study reported the best outcome with cartilaginous and worst with spindle cell and sarcomatoid. The most common differentiation in our set up was cartilaginous (35\%) followed by squamous $(32.5 \%)$. This is consistent with the most common subtype reported in literature, squamous carcinoma 
Table 4. Comparison of Outcomes with the Western Population in the Study by El Zein et al

\begin{tabular}{|c|c|c|c|}
\hline Clinicopathological Parameters & & Our Study & Study by El Zein et al \\
\hline \multirow[t]{2}{*}{ Age (Years) } & Median & 41.5 & 50 \\
\hline & Range & 19 to 78 & 42 to 90 \\
\hline \multirow[t]{3}{*}{ TNM Staging $(\mathrm{n}=40)$} & Stage I & 0 & $12(30 \%)$ \\
\hline & Stage II & $25(62.5 \%)$ & $23(57.5 \%)$ \\
\hline & Stage III & $15(37.5 \%)$ & $5(12.5 \%)$ \\
\hline \multirow[t]{2}{*}{ NACT Given(n=40) } & Yes & $17(42.5 \%)$ & $9(22.5 \%)$ \\
\hline & No & $23(57.5 \%)$ & $31(77.5 \%)$ \\
\hline \multirow{4}{*}{$\begin{array}{l}\text { Hormonal Status } \\
(n=40 \text { ours } n=46 \text { for } Z \text { Zein et al) }\end{array}$} & Triple Negative & $38(95 \%)$ & $37(80.4 \%)$ \\
\hline & ER & 2 & 4 \\
\hline & PR & 2 & 6 \\
\hline & Her 2 neu & 0 & 3 \\
\hline \multirow[t]{2}{*}{ Surgery Performed $(n=40)$} & $\mathrm{BCS}$ & $13(32.5 \%)$ & $17(42.5 \%)$ \\
\hline & Mastectomy & $27(67.5 \%)$ & $23(57.5 \%)$ \\
\hline \multirow[t]{2}{*}{ Pathological Tumour size $(\mathrm{cm})$} & Median & 5.4 & 3.1 \\
\hline & Range & 2.1 to 22 & 0.5 to 14 \\
\hline \multirow{4}{*}{$\begin{array}{l}\text { Predominant type of differentiation } \\
(n=40 \text { and } n=46)\end{array}$} & Cartilaginous & 14 & 3 \\
\hline & Squamous & 13 & 12 \\
\hline & Mesenchymal & 0 & 17 \\
\hline & Spindle cell & 4 & 4 \\
\hline \multirow[t]{2}{*}{ Histology $(n=40$ and $n=46)$} & Pure metaplastic & $28(70 \%)$ & $9(19.6 \%)$ \\
\hline & Mixed metaplastic & $12(30 \%)$ & $37(80.4 \%)$ \\
\hline \multirow[t]{3}{*}{ Clinical Outcomes $(\mathrm{n}=40)$} & Alive and disease free & $18(45 \%)$ & $15(37.5 \%)$ \\
\hline & Alive with local recurrence/metastasis & $5(12.5 \%)$ & $13(32.5 \%)$ \\
\hline & Mortality & $17(42.5 \%)$ & $12(30 \%)$ \\
\hline
\end{tabular}

(40\%), followed by matrix-producing/mesenchymal and cartilaginous MBC (Choi et al., 2012; Jia et al., 2019; Puii et al., 2020). However, there were no matrix producing tumor in our study. Almost all the patients had a triple negative tumor $(95 \%)$ in our study, which was more than the reported percentage in the literature ranging between

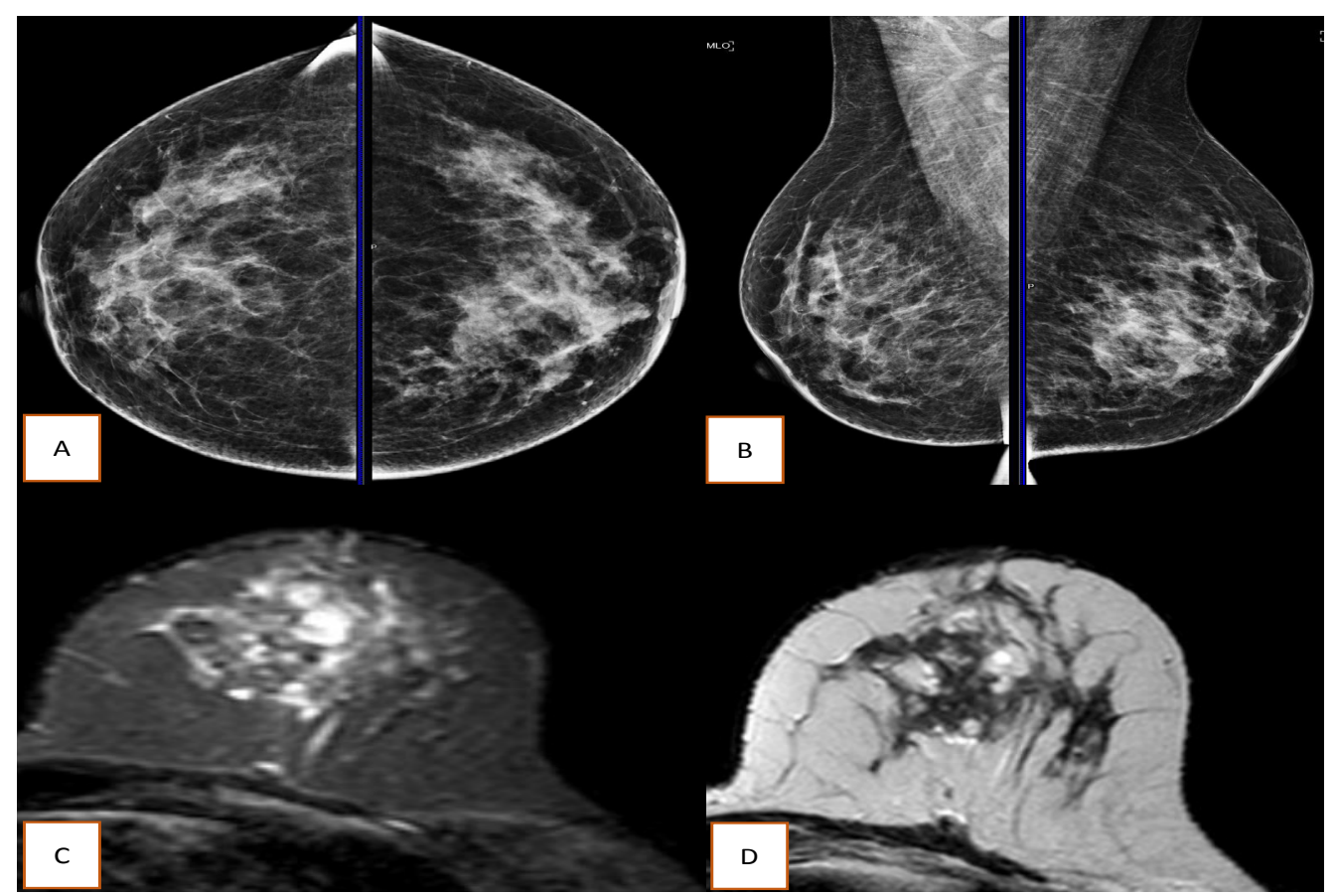

Figure 3. Mammographic and MRI features of MBC. A \& B, Focal asymmetry in the left breast without any lump on mammography; C, MRI of the left breast showing T2 hyperintensity; D, Same lesion showing peripheral enhancement with surrounding non-mass clustered rim enhancement on the diffusion weighted imaging sequence of MRI. 


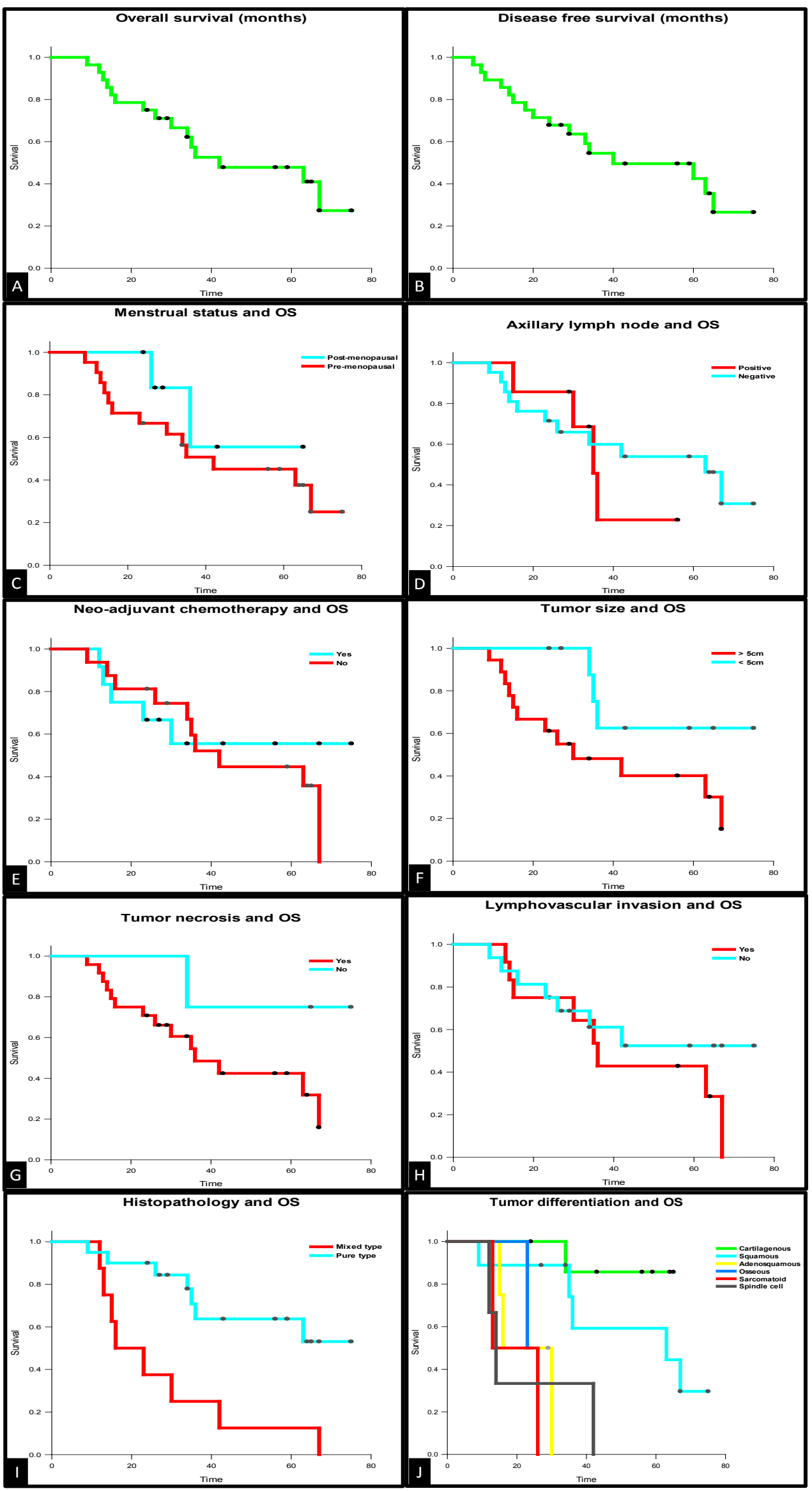

Figure 4. Kaplan-Meier Survival curves. A, Overall survival (OS) of our study cohort; B, Disease-Free Survival (DFS) of our study cohort; C-J, Subgroup Kaplan-Meyer survival analysis of Overall survival with various factors as mentioned. Tissue differentiation, MBC histology and tumor size $>5 \mathrm{~cm}$ affected the OS and DFS significantly. Whereas tumour necrosis, lympho-vascular invasion and axillary lymph node involvement showed stark difference in the survival months but this was not statiscally significant. 
$70 \%$ and $85 \%$ (Leibl et al., 2005; Beatty et al., 2006; Tse et al., 2006; Casey et al., 2007; El Zein et al., 2017). There was no Her $/$ neu enriched tumor in our cohort, but the reported positivity is $0-25 \%$ in the literature (Ong et al., 2018). There are other IHC markers such as Cytokeratin, Vimentin, S-100, SMA, Bcl-2, p63 and CD34 which help to differentiate these tumors from their close differential diagnosis. These are primary sarcoma of breast, myoepithelial breast carcinoma, myofibroblastic tumors, phyllodes tumors, nodular fasciitis, fibromatosis, and pleomorphic adenoma (Arias-Stella et al., 2018). These are usually CD 34 negative as it is positive in phyllodes, and sarcoma of the breast. Although mixed tumors are rare, there are case reports of $\mathrm{MBC}$ with cartilaginous differentiation with a co-existing foci chondrosarcoma with lympho-vascular invasion (Vias et al.,2019).

Our study includes an extensive follow up of the patients and only six were lost to follow up out of 46 $(13.04 \%)$. At the time of conclusion of study, $45 \%$ were alive and disease free, $12.5 \%$ were alive and disease free and there was $42.5 \%$ mortality, out of which $11.7 \%$ patients died of non-disease related causes. Out of those died due to disease related causes, $86.66 \%$ died of metastasis and $13.34 \%$ due to loco-regional reccurence. Overall metastasis was present in $40 \%$ cases and locoregional recurrence in $10 \%$ patients. This is consistent with the literature reports of $5-12 \%$ of loco-regional recurrence and about $40 \%$ of metastatic disease (Luini et al., 2007; Song et al., 2013; Edenfield et al., 2017). The route of metastasis is by hematogenous invasion, resulting in bone and lung metastasis (Luini et al., 2007). The survival of the patients with $\mathrm{MBC}$ is decreased as compared to the IDC (Ong et al., 2018; Han et al., 2019). The overall survival (OS) in our cohort was 42 months, in accordance with the reported survival is 48-60 months (Fayaz et al., 2017; Pukkala et al., 2018). The largest series reported from India with 31 patients reported survival to be 39 months (Puii et al., 2020). Axillary lymph node involvement reduced the OS in our study, but this was not significant statistically. Post-menopausal patients had better survival, since this tumor is not associated with hormone receptors, this can be explained by the unfavourable biology of the tumor originating at an early age. Another interesting finding highlighted by our study was the decreased survival in those not receiving NACT, which might shed a light on the role of chemotherapy in this disease. There was no mortality in the group of 4 patients who did not have necrosis in their final histopathology and thus both OS and DFS for that group was not reached compared to OS and DFS 36 months and 40 months, respectively, in patients with presence of tumor necrosis. Similar finding was seen in case of lympho-vascular invasion of the tumor. However, both of these were not statistically significant. The survival outcome in our study was significantly affected by the tumor size more than $5 \mathrm{~cm}$, type of differentiation and pure or mixed histology of the tumor. In a study at the Johns Hopkins, OS with tumors more than $5 \mathrm{~cm}$ was decreased as compared to those presented with tumors less than $2 \mathrm{~cm}$ (Fayaz et al., 2017). It also confirms the poor prognosis of this disease with 5 years OS of only $54.8 \%$, as compared with of $86 \%-88 \%$ in breast cancer as reported in the Nordic Cancer Registry between 2000 and 2014 (Pukkala et al., 2018).

The findings of our study were contrasted to a study done in the western population with a comparable sample size (El Zein et al., 2017). It included 46 patients of MBC with a subgroup analysis done of 40 patients. A comparison was made, as shown in table 4 . In their population, the median age was 50 years with $12(30 \%)$ presenting in stage I. The median tumor size was $3.1 \mathrm{~cm}$ with maximum tumor being $14 \mathrm{~cm}$. Predominant histology was mesenchymal (17 cases) while pure MBC was noted only in 9 cases. The mortality was in $12(30 \%)$ patients with recurrence and/ or metastasis seen in $13(32.5 \%)$ patients. Our patients presented at a much younger age, but also at later stage. Most of our patients were at stage II while $30 \%$ of the western population were detected in stage I. Moreover, the tumor size in our population is bigger $(5.4 \mathrm{vs} .3 .1 \mathrm{~cm})$. This can be attributed to early detection and probably a less aggressive disease in the western population as also has been evident from lower mortality compared to ours $(42.5 \%$ vs $30 \%)$. Few other studies have reported OS of 54-83\% (Toumi et al., 2011; Abouharb et al., 2012; Esbah et al., 2012; Cimino-Mathews et al., 2016; Langlands er al., 2016; Jha et al., 2017)

This is the first study of its kind from the Indian population on metaplastic breast cancer with extensive follow up and analysis of prognostic factors. To the best of our knowledge, this study reports the maximum number of cases from the country. The limitation of this study is the retrospective component with selection bias. The study was conducted in a single institute. The study was concluded in a short interval (5 months) after the last recruitment so 5-year survival rates could not be calculated.

Metaplastic breast cancer is a heterogeneous disease encompassing biologically different tumor classes with variable outcome. Metaplastic breast cancer in the Indian setup presents in younger patients with aggressive large tumors at a higher stage and diverse histopathology and with comparable overall and disease-free survival. Histological subtype, differentiation and tumor size are prognostic factors. There is a need for a multi-institutional prospective study with detailed pathological analysis with longer follow up period for identifying definitive prognostic and predictive factors for developing a standardised management regimen.

\section{Author Contribution Statement}

We would like to acknowledge the contribution of the various authors, starting from author 1 in data collection and writing the manuscript, author 2 for the data analysis and manuscript writing, author 3 for the extensive clinical follow up, author 4 and 5 for editing the manuscript, author 6 to provide the radiological correlation, author 7 for the pathological outcomes and author 8 and 9 for conceptualisation and their constant guidance.

\section{Acknowledgements}

There was no external funding sought for this study. 
This study was done independently of any thesis or a scientific project. This study was a part of routine follow up of the patients in our BCC clinic, so no additional ethical clearance was taken. It was not registered with any scientific body as it is an observational study.

\section{Statement conflict of Interest}

No conflict of interest.

\section{References}

Abbas-zadeh tavassoli F (1992). Classification of metaplastic carcinomas of the breast. Pathol Annual, 27, 89-119.

Abouharb S, Moulder S (2015). Metaplastic breast cancer: clinical overview and molecular aberrations for potential targeted therapy. Curr Oncol Rep, 17, 10.

Al Sayed AD, El Weshi AN, Tulbah AM, et al (2006). Metaplastic carcinoma of the breast clinical presentation, treatment results and prognostic factors. Acta Oncol, 45, 188-95.

Alam K, Maheshwari V, Harris H, et al (2003). An unusual case of metaplastic breast carcinoma (sarcomatoid variant). Indian J Surg, 65, NA-NA.

Arias-Stella JA, Alvarado-Cabrero I, Pareja F (2018). Special Types of Invasive Breast Carcinoma. In Practical Atlas of Breast Pathology. Springer, Cham, pp 263-92.

Aydiner A, Sen F, Tambas M, et al (2015). Metaplastic breast carcinoma versus triple-negative breast cancer: Survival and Response to Treatment. Medicine (Baltimore), 94, e2341.

Beatty JD, Atwood M, Tickman R, Reiner M (2006). Metaplastic breast cancer: clinical significance. Am J Surg, 191, 657-64.

Carey LA, Dees EC, Sawyer L, et al (2007). The triple negative paradox: primary tumor chemosensitivity of breast cancer subtypes. Clin Cancer Res, 13, 2329-34.

Choi BB, Shu KS (2012). Metaplastic carcinoma of the breast: multimodality imaging and histopathologic assessment. Acta Radiol, 53, 5-11.

Cimino-Mathews A, Verma S, Figueroa-Magalhaes MC, et al (2016). A clinicopathologic analysis of 45 patients with metaplastic breast carcinoma. Am J Clin Pathol, 145, 365-72.

Corso G, Frassoni S, Girardi A, et al (2021). Metaplastic breast cancer: prognostic and therapeutic considerations. J Surg Oncol, 123, 61-70.

Donato H, Candelária I, Oliveira P, et al (2018). Imaging findings of metaplastic carcinoma of the breast with pathologic correlation. J Belgian Soc Radiol, 102.

Edenfield J, Schammel C, Collins J, et al (2017). Metaplastic breast cancer: Molecular typing and identification of potential targeted therapies at a single institution. Clin Breast Cancer, 17, e1-e10.

El Zein D, Hughes M, Kumar S, et al (2017). Metaplastic carcinoma of the breast is more aggressive than triplenegative breast cancer: a study from a single institution and review of literature. Clin Breast Cancer, 17, 382-91

Esbah O, Turkoz FP, Turker I, et al (2012). Metaplastic breast carcinoma: case series and review of the literature. Asian Pac J Cancer Prev, 13, 4645-9.

Fayaz S, Demian GA, Eissa HES, et al (2017). Metaplastic breast carcinoma: Analysis of 31 cases from a single institute. J Egypt Natl Canc Inst, 29, 141-5.

Gadaleta-Caldarola G, Nenna R, Lanotte L, et al (2021). Metaplastic breast cancer: an old histotype but a current therapeutic problem. Future Oncol, 17, 955-63.

Gradishar WJ, Anderson BO, Balassanian R, et al (2018). Breast Cancer, Version 4.2017, NCCN Clinical Practice Guidelines in Oncology. J Natl Compr Canc Netw, 16, 310-20.

Han M, Salamat A, Zhu L, et al (2019). Metaplastic breast carcinoma: a clinical-pathologic study of 97 cases with subset analysis of response to neoadjuvant chemotherapy. Mod Pathol, 32, 807-16.

Hashmi AA, Aijaz S, Mahboob R, et al (2018). Clinicopathologic features of invasive metaplastic and micropapillary breast carcinoma: comparison with invasive ductal carcinoma of breast. BMC Res Notes, 11, 531.

He X, Ji J, Dong R, et al (2019). Prognosis in different subtypes of metaplastic breast cancer: a population-based analysis. Breast Cancer Res Treat, 173, 329-41.

Hennessy BT, Giordano S, Broglio K, et al. (2006). Biphasic metaplastic sarcomatoid carcinoma of the breast. Ann Oncol, 17, 605-13.

Jha A, Agrawal V, Tanveer N, Khullar R (2017). Metaplastic breast carcinoma presenting as benign breast lump. J Cancer Res Ther, 13, 593.

Jia Y, He C, Liu L, et al (2019). A retrospective study of the imaging and pathological features of metaplastic breast carcinoma and review of the literature. Int Med J Exp Clin Res, 25, 248.

Lai HW, Tseng LM., Chang TW, et al (2013). The prognostic significance of metaplastic carcinoma of the breast (MCB)-a case-controlled comparison study with infiltrating ductal carcinoma. Breast J, 22, 968-973.

Lakhani SR, Ellis IO, Schnitt S, et al (2012). WHO Classification of Tumors of the Breast.

Langlands F, Cornford E, Rakha E, et al (2016). Imaging overview of metaplastic carcinomas of the breast: a large study of 71 cases. Br J Radiol, 89, 20140644.

Leddy R, Irshad A, Rumboldt T, et al (2012). Review of metaplastic carcinoma of the breast: imaging findings and pathologic features. J Clin Imaging Sci, 2.

Lee H, Jung SY, Ro JY, et al (2012). Metaplastic breast cancer: clinicopathological features and its prognosis. J Clin Pathol, 65, 441-6.

Leibl S, Moinfar F (2005). Metaplastic breast carcinomas are negative for Her-2 but frequently express EGFR (Her-1): potential relevance to adjuvant treatment with EGFR tyrosine kinase inhibitors?. J Clin Pathol, 58, 700-4.

Li Y, Chen M, Pardini B, et al (2019). The role of radiotherapy in metaplastic breast cancer: a propensity score-matched analysis of the SEER database. J Transl Med, 17, 318.

Luini A, Aguilar M, Gatti G, et al (2007). Metaplastic carcinoma of the breast, an unusual disease with worse prognosis: the experience of the European Institute of Oncology and review of the literature. Breast Cancer Rese Treat, 101, 349-53.

Ma Y, Yang Z, Gao Y, et al (2021). Research on the role of combined chemotherapy and radiotherapy in patients with $\mathrm{N}+$ non-metastatic metaplastic breast carcinoma: A Competing Risk Analysis Model Based on the SEER database, 2000 to 2015. Front Oncol, 22, 3082.

Moorman AM, Vink R, Rutgers EJT, et al (2020). Incidence, clinical features, and outcomes of special types in breast cancer in a single institution population. Breast $J, \mathbf{2 6}$, 2163-9.

Nayak A, Wu Y, Gilcrease MZ (2013). Primary squamous cell carcinoma of the breast: predictors of locoregional recurrence and overall survival. Am J Surg Pathol, 37, 867-73.

Ong CT, Campbell BM, Thomas SM, et al (2018). Metaplastic breast cancer treatment and outcomes in 2500 patients: a retrospective analysis of a national oncology database. Ann Surg Oncol, 25, 2249-60.

Pezzi CM, Patel-Parekh L, Cole K, et al (2007). Characteristics and treatment of metaplastic breast cancer: analysis of 892 cases from the National Cancer Data Base. Ann Surg Oncol, 14, 166-73. 
Pitts WC, Rojas VA, Gaffey MJ, et al (1991). Carcinomas with metaplasia and sarcomas of the breast. Am J Clin Pathol, 95, 623-32.

Puii L, Sarathy V, Sangi L, et al (2020). Survival outcomes of metaplastic breast carcinoma: An Indian tertiary care center data. J Clin Oncol, 2020, e12579-e12579.

Pukkala E, Engholm G, Højsgaard Schmidt LK, et al (2018). Nordic Cancer Registries-an overview of their procedures and data comparability. Acta Oncol, 57, 440-55.

Rayson D, Adjei AA, Suman VJ, et al (1999). Metaplastic breast cancer: prognosis and response to systemic therapy. Ann Oncol, 10, 413-9.

Schwartz TL, Mogal H, Papageorgiou C, et al (2013). Metaplastic breast cancer: histologic characteristics, prognostic factors and systemic treatment strategies. Exp Hematol Oncol, 2, 1-6.

Song Y, Liu X, Zhang G, et al (2013). Unique clinicopathological features of metaplastic breast carcinoma compared with invasive ductal carcinoma and poor prognostic indicators. World J Surg Oncol, 11, 1-9.

Tadros AB, Sevilimedu V, Giri DD, et al (2021). Survival outcomes for metaplastic breast cancer differ by histologic subtype. Ann Surg Oncol, 28, 4245-53.

Toumi Z, Bullen C, Tang AC, Dalal N, Ellenbogen S (2011). Metaplastic breast carcinoma: a case report and systematic review of the literature. Pathol Int, 61, 582-8.

Tse GM, Tan PH, Putti TC, et al (2006). Metaplastic carcinoma of the breast: a clinicopathological review. J Clin Pathol, 59, 1079-83.

Vias P, Pandey AK, Dimri K, et al (2019). Metaplastic carcinoma with foci of chondrosarcoma in breast: A Rare Case. Asian Pac J Cancer Care, 4, 131-3.

Wang J, Zhang WW, Lian CL, et al (2019). The effect of post-mastectomy radiotherapy in patients with metaplastic breast cancer: An Analysis of SEER Database. Front Oncol, 9, 747

Yu JI, Choi DH, Huh SJ, et al (2015). Unique characteristics and failure patterns of metaplastic breast cancer in contrast to invasive ductal carcinoma: a retrospective multicenter case-control study (KROG 13-07). Clin Breast Cancer, 15, 105-15.

Zhang J, Yang C, Lei C, et al (2021). Survival outcomes after breast-conserving therapy compared with mastectomy for patients with early-stage metaplastic breast cancer: a population-based study of 2412 patients. Breast J, 1, 10-7.

Zhang Y, Lv F, Yang Y, et al (2015). Clinicopathological features and prognosis of metaplastic breast carcinoma: experience of a major Chinese cancer center. PLoS One, 10, e0131409.

This work is licensed under a Creative Commons AttributionNon Commercial 4.0 International License. 